\title{
Regularities in the Formation of the Structure and Properties of Coatings Based on Silicate Paint Sol
}

\author{
V. Loganina ${ }^{(\bowtie)}$, E. Mazhitov, and V. Demyanova \\ Department "Quality Management and Technology of Construction Production", \\ Penza State University of Architecture and Construction, Penza, Russia \\ loganin@mail.ru
}

\begin{abstract}
The authors established a higher quality of the appearance of coatings based on silicate paint sol in comparison with coatings based on silicate paints. Information is provided on the regularities in the formation of the quality of the appearance of coatings on the basis of silicate paint sol is that the silicate paint sol has a higher value coefficient of the wetting and spreading on the cement substrate in comparison with silicate paint. It was established that when using a paint brush on the cement substrate, there has been some slowing of the rise time of the structure of silicate paint compositions based on polysilicate solutions. A higher value of the adhesion work based on polysilicate solutions were indentified, indicating the strong force of the paint and the cement substrate.
\end{abstract}

Keywords: Sol silicate paint - Polysilicate binder - Coatings - Wetting · Coating quality

\section{Introduction}

The problem of reliability and durability of protective decorative coatings of exterior walls of buildings is one of the topical scientific and technical objectives in materials science. It is known that the longevity of coatings depend on the type of binder, the technology of applying the paint composition, operating conditions, etc. (Ailer 1982). In the practice of finishing works, silicate paints, which are a suspension of pigments and fillers in liquid glass of potassium, proved to be very useful. To improve the performance of coatings based on silicate paints, it is important to develop methods for modifying liquid glass. Analysis of patent and scientific-technical literature shows that one way of modification is the introduction of organosilicon and other polymeric compounds into the binder. In works (Figovsky et al. 2012) there is an increased durability of silicate coatings when imposing of polymeric compounds. It is of interest to use polysilicates in silicate paints as film-forming substances that provide higher performance properties of coatings. However, at present time the questions of the formation of the structure and properties of coatings based on sol silicate paints have not been studied, the questions of mechanism for improving the operational properties of coatings based on them have not been considered. Polysilicates are characterized by 
a broad range of the degree of polymerization of anions and are dispersions of colloidal silica in an aqueous solution of alkali metal silicates. We have established a paint composition based on a polysilicate binder obtained by mixing liquid glass with a silica sol (Loganina et al. 2018a, b). It was found, that coatings based on polysilicate solutions are characterized by faster curing. Films based on polysilicate solutions have higher cohesive strength. The tensile strength of a film based on potassium liquid glass is $\mathrm{Rp}=0.392 \mathrm{MPa}$, and the tensile strength of a film based on a polysilicate solution (15\% Nanosil 20) is $1.1345 \mathrm{MPa}$. The paint forms a coating characterized by a uniform homogeneous surface.

To study the regularities in the formation of the quality of the appearance of coatings on the based on sol silicate paint, the character of filling on a porous cement substrate was considered.

\section{Methods and Approaches}

The character of the filling of the sol of the silicate paint was evaluated. The method of determining filling consisted in applying five parallel strips of paint and determining the degree of spreadability according to the number of stuck bands. Paint with an operating viscosity was applied to a glass plate measuring $200 \times 100 \times 1.2 \mathrm{~mm}$. The spreading of five parallel strips was evaluated on a ten-point scale of filling.

The surface tension of the paint was determined by the drop method (stalagmometric method). Work of adhesion of the paint to a cement substrate was calculated using the Dupre - Young thermodynamic equation. The wetting operation and spreading coefficient were determined.

The quality of the appearance of the coatings was estimated from the surface roughness $\mathrm{Ra}$ by the method of scanning probe microscopy (SPM) (Chizhik and Syroezhkin 2010).

\section{Results and Discussion}

Previously, the rheological type of the solutions was determined. The rheological properties were evaluated by the indicators of conventional viscosity according to B34 , critical shear stress with instrument Reotest-2. It is found, that all systems are typical pseudoplastic bodies. In the region of slow flow, the viscosity of polysilicate solutions gradually declined with increasing shear stress.

Analysis of data (Table 1) shows, that silicate paints based on polysilicate solutions have a long filling time. Thus, the time for bottling for a paint based on liquid glass is $6 \mathrm{~min}$, and for a paint based on a polysilicate solution - $8 \mathrm{~min} 40 \mathrm{~s}$. The degree of filling is satisfactory (no more than $10 \mathrm{~min}$ ). For paints based on a polysilicate solution, a large work of adhesion to the substrate is characteristic. So, work of the adhesion of paint based on the potassium polysilicate solution to the substrate is $108.17 \mathrm{mN} / \mathrm{m}$, while work of the adhesion of the paint based on potassium liquid glass is $96.82 \mathrm{mN} / \mathrm{m}$. A higher value of work of the adhesion of paint based on polysilicate solutions indicates a stronger interaction of the paint and the cement substrate. 
Table 1. Test results

\begin{tabular}{l|l|l}
\hline \multirow{2}{*}{ The name of indicators } & \multicolumn{2}{|l}{ Name of the paint composition } \\
\cline { 2 - 3 } & $\begin{array}{l}\text { Based on potassium } \\
\text { liquid glass }\end{array}$ & $\begin{array}{l}\text { Based on potassium } \\
\text { polysilicate solution }\end{array}$ \\
\hline Surface roughness, $\mathrm{Ra},[\mu \mathrm{m}]$ & 16,208 & 10,880 \\
\hline The contact angle of wetting & 50,9 & 51,6 \\
\hline $\begin{array}{l}\text { Surface tension of the paint } \\
\text { composition, }[\mathrm{mN} / \mathrm{m}]\end{array}$ & 59,38 & 66,73 \\
\hline Filling the colorful composition * & 7 min $40 \mathrm{~s}$ & 8 min $40 \mathrm{~s}$ \\
\hline Adhesion work, $[\mathrm{mN} / \mathrm{m}]$ & 9 & 9 \\
\hline Wetting operation, $[\mathrm{mN} / \mathrm{m}]$ & 96,82 & 108,17 \\
\hline Cohesion work, $[\mathrm{mN} / \mathrm{m}]$ & 37,44 & 41,44 \\
\hline Coefficient of spreading $[\mathrm{mN} / \mathrm{m}]$ & 118,76 & 133.46 \\
\hline Coefficient of wetting & $-21,94$ & $-25,29$ \\
\hline Note & 0,815 & 0,81 \\
\hline
\end{tabular}

Note: * Above the line are the values of time of restoration of the paint structure, below the line the value of filling

The work of wetting paints based on polysilicate solution is higher, which indicates better wetting of the paint surface of the cement substrate. Thus, the work of wetting the sol of silicate paint on the basis of potassium polysilicate solution is $41,44 \mathrm{mN} / \mathrm{m}$, and on the basis of potassium liquid glass $-37.44 \mathrm{mN} / \mathrm{m}$. When the sol of the silicate paint is applied to the substrate, the wetting and spreading coefficient increases, which indicates more favorable conditions for the formation of the quality of the appearance. The surface roughness of the coating based on silicate paint is $\mathrm{Ra}=16.208 \mu \mathrm{m}$, and based on the potassium polysilicate solution, $\mathrm{Ra}=10.880 \mu \mathrm{m}$. The quality of the appearance of the surface of the coatings formed by the sol with silicate paint, in accordance with GOST 9.032-74 ** "Unified system for protection against corrosion and aging. Coatings for paint and varnish, Groups, technical requirements and designations" is graded IV class, and on the basis of liquid glass - V class.

Testing of solution samples, colored with sol by silicate paint, was carried out for frost resistance by alternating thawing and freezing. Appearance of coatings was assessed according to GOST 6992-68. "Coatings for paint and varnish. Test method for resistance to atmospheric conditions". It was found, that coatings on the basis of the developed composition had withstood 40 test cycles, while the coating condition after 40 test cycles was estimated at I.1 points, which corresponds to the coating condition with no color change, chalking, mud retention.

To assess the waterproof properties of coatings, tests were carried out of solution samples stained with silicate and sol silicate paints. After curing of the coatings, water absorption was determined upon capillary suction. It was found, that water absorption by capillary suction of samples stained with silicate paint is $4.4 \%$, and stained with silicate paint $-4.6 \%$. The lower value of water saturation of samples colored with sol by silicate paint indicate a change in the pore size in the coating structure as compared to the coating based on silicate paint. 
Higher waterproof properties of coatings based on sol silicate paint are caused, in our opinion, by the structure of the coating. Scanning probe microscopy (SPM) methods were used to estimate the local structure of the coating surface. It is established, that the surface of coatings based on potassium liquid glass contains a certain number of pores of the nanometric range, differing in size and shape. The maximum pore size is $19.8 \mu \mathrm{m}$. Pores with a diameter of 18.85 to $19.6 \mu \mathrm{m}$ are mainly present, whereas in the coating based on the potassium polysilicate solution there are two groups of pores: from 19.25 to $19.8 \mu \mathrm{m}$ and from 20.0 to $20.6 \mu \mathrm{m}$. The value of the maximum pore size is $21.2 \mu \mathrm{m}$. In the coating based on the polysilicate solution is observed a more uniform pore size distribution.

Coatings based on the developed paint are characterized by high adhesion (1.1$1.3 \mathrm{MPa}$ ), coefficient of vapor permeability $-0,00878 \mathrm{mg} / \mathrm{m} * \mathrm{hPa}$.

\section{Conclusions}

The properties of the paint and coating based on it meet the requirements for coatings for exterior decoration of buildings, have higher adhesion, sufficient vapor permeability.

\section{References}

Ailer P (1982) The chemistry of silica (Transl. from English), Part 1. Mir, Moscow, p. 416

Chizhik SA, Syroezhkin SV (2010) Methods of scanning probe microscopy in micro- and nanomechanics. Instr Meas Methods 1:85-94

Figovsky O, Borisov Yu, Beilin D (2012) Nanostructured binder for acid-resisting builder materials. J Sci Israel-Technol Advant 14(1):7-12

Loganina VI, Kislitsyna SN, Mazhitov YB (2018a) Development of sol-silicate composition for decoration of building walls. Case Stud Constr Mater 9:e00173

Loganina VI, Kislitsyna SN, Mazhitov YB (2018b) Properties of polysiylate binders for solsilicate pains. Adv Mater Res 1147:1-4

Open Access This chapter is licensed under the terms of the Creative Commons Attribution 4.0 International License (http://creativecommons.org/licenses/by/4.0/), which permits use, sharing, adaptation, distribution and reproduction in any medium or format, as long as you give appropriate credit to the original author(s) and the source, provide a link to the Creative Commons license and indicate if changes were made.

The images or other third party material in this chapter are included in the chapter's Creative Commons license, unless indicated otherwise in a credit line to the material. If material is not included in the chapter's Creative Commons license and your intended use is not permitted by statutory regulation or exceeds the permitted use, you will need to obtain permission directly from the copyright holder.

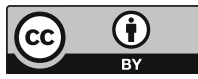

